\title{
New Compensation Mechanism of Load Aggregator in China Based on User Satisfaction
}

\author{
Shaomei Yang, Dongjiu Chen* \\ Department of Economics and Management, North China Electric Power University, Baoding, China
}

Received: 5 November 2018

Accepted: 29 May 2019

\begin{abstract}
In recent years, the excessive load at peak time affects the stable operation of the power grid. The load aggregator can aggregate loads of users to achieve the goal of peak clipping and valley filling. Based on satisfaction degree of electricity consumption and compensation for users, this paper studies the marginal unit compensation price of interruptible load and transferable load of users. Then this paper puts forward an appropriate compensation mechanism of the grid company to the load aggregator and the load aggregator to users. Finally, the costs and benefits of each participant are analyzed in an attempt to verify the feasibility of the compensation mechanism. The results show that, by load aggregation, all participants can make a profit and carbon dioxide emissions will be reduced.
\end{abstract}

Keywords: load aggregator, compensation mechanism, costs and benefits

\section{Introduction}

In recent years, the contradiction between China's power supply and demand has become more and more prominent. The daily peak-to-valley difference of Jiangsu Province was 20.58 million $\mathrm{kw}$, while the annual peak of electricity consumption (5\%) lasted only 24.5 hours [1]. If the installed capacity is increased only to meet the requirement of the short-term peak power consumption, the resource utilization efficiency will be low [2]. Through the scheduling of a flexible load of users, mainly including interruptible load and transferable load, the condition of the power grid can be improved to some extent. However, the flexible load of a single user is too small to contract with the grid company [3]. The load aggregator (LA) can integrate a flexible load of users through certain incentives

*e-mail: 1151935527@qq.com and participate in market transactions, and it can also get paid from it [4]. Through the aggregation of load aggregators, the peak load and the spare capacity of the power grid can be reduced, the investment in power grid construction will be delayed, and the economics and safety of the power system operation are improved. In addition, users and LA can obtain economic benefits and the emission of pollutants can be reduced $[2,5]$.

Previous papers about load aggregators are mainly divided into two categories: scheduling strategies of LA [6-9] and operating price mechanisms of LA [10-13].

Liu et al. proposed a two-stage optimization method. In the first stage, users form power consumption plans based on the electricity price information and feedback to LA. In the second stage, LA formulates the compensation price according to the residential electricity consumption plan and the goal of maximizing self-interest, and then users form consumption plans based on the compensation price [6]. Liu et al. proposed the schedule of the flexible load in real time by 
considering the bid amount and satisfaction of users [7]. Sun et al. established an assessment method model of response potential level of users [8]. LI et al. established a two-layer scheduling model with various load priority scheduling values at the macro level and proposed a consumption sharing strategy that maximizes the benefits of LA at the micro level [9].

$\mathrm{Hu}$ et al. divided users into cooperative users and non-cooperative users, and proposed a price mechanism that increases with load [10]. Zhang et al. proposed a dynamic compensation price mechanism based on supply and demand status [11]. Other studies proposed a tiered compensation system. When the user's interrupted load reaches a certain amount, the new unit price is used to compensate the excess $[12,13]$.

However, it is not clear how to formulate compensation mechanisms based on the satisfaction degree of users. This paper establishes an appropriate compensation mechanism of interruptible load and transferable load based on the satisfaction degree of users. The costs and benefits of users, LA and the grid company are analyzed and the feasibility of the compensation scheme was verified by a case study.

\section{Material and Methods}

LA is an intermediary institution that connects the power company with users and forms a principalagent relationship with the power company. The grid company is the entrusting party, which is responsible for providing relevant information of the grid and users. LA is the agent and needs to properly schedule according to the information provided by the grid company and the user to achieve the maximum value of its own interests [14-19].

Interruptible load is the load that can be reduced at a certain time, mainly including electric appliances with thermal inertia, such as air conditioners, refrigerators, and electric heaters. The load can be reduced by cycle start and stop, and LA can obtain direct control of the interruptible load through the contract. Transferable load is the load that can change the usage time, including washing machines, dishwashers, electric vehicles, etc.

\section{Compensation Mechanism of Interruptible Load}

The satisfaction degree of users is mainly related to the amount of interruptible load and compensation amount. The greater the power consumption, the higher the satisfaction degree of users. The larger the compensation amount, the higher the satisfaction degree of users. Since the dimensions of the two indicators are different, the values need to be preprocessed [20-24].

Define indicator of electricity consumption of users:

$$
h_{t}=\frac{p_{t}^{0}-p_{t}^{\prime}}{p_{t}^{0}}
$$

...where $p_{t}^{0}$ is the maximum load that a user can interrupt at time $t$, and $p_{t}{ }^{\prime}$ is the amount of load interrupted by LA at time $t$.

The larger $h_{t}$ is, the higher satisfaction degree of the user. This paper considers that users are less sensitive to the amount of interruptible load and more sensitive to the time duration of interruptible load, namely the proportion of the load interrupted by LA to the maximum interruptible load of a user:

$$
f_{t}=\frac{p_{t}^{\prime}}{p_{t}^{0}}
$$

...where $f_{t}$ is the proportion of the load interrupted by LA to the maximum interruptible load of a user. Therefore:

$$
h_{t}=1-f_{t}
$$

Define compensation amount of a user:

$$
b_{1, t}=p_{t}^{0} \int_{0}^{f_{t}} c(f) d f
$$

...where $b_{1, t}$ is the compensation amount obtained by the user at time $t$, and $c(f)$ is the compensation unit price for the $f$ th interruptible load of users, which is called the marginal unit compensation price in this paper.

Define indicator of compensation amount of a user:

$$
g_{t}=\frac{p_{t}^{0} \int_{0}^{f_{t}} c(f) d f}{p_{t}^{0} c_{t}^{0}}=\frac{\int_{0}^{f_{t}} c(f) d f}{c_{t}^{0}}
$$

...where $c_{t}^{0}$ is the unit price of electricity at time $t$. The larger $g_{t}$ is, the higher satisfaction degree of the user. Since the sensitivity of users to the above two indicators is different, the definition of satisfaction degree of the user is:

$$
w_{t}\left(f_{t}\right)=h_{t}^{{ }^{w_{1}}} g_{t}{ }^{w_{2}} \quad w_{1}+w_{2}=1, w_{1}, w_{2}>0
$$

...where $c_{t}(f)$ is the satisfaction degree of a user when the proportion of interrupted load to the maximum interruptible load is $f_{t} . w_{1}$ is the sensitivity of the user to electricity consumption. The larger $w_{1}$ is, the more sensitive the user is to electricity consumption. $w_{2}$ is the sensitivity of the user to the compensation amount. The larger $w_{2}$, the more sensitive the user is to the compensation amount.

If LA wants to interrupt more electricity at time $t$, the satisfaction degree of the user can't decrease, namely:

$$
w_{t}\left(f_{t}\right) \leq w_{t}\left(f_{t}+\Delta f\right)
$$

Namely: 
$\left(1-f_{t}\right)^{w_{1}}\left(\frac{\int_{0}^{f_{t}} c(f) d f}{c_{t}^{0}}\right)^{w_{2}} \leq\left[1-\left(f_{t}+\Delta f\right)\right]^{w_{1}}\left(\frac{\int_{0}^{f_{t}+\Delta f} c(f) d f}{c_{t}^{0}}\right)^{w_{2}}$

To get the minimum marginal unit compensation price, we have:

$\left(1-f_{t}\right)^{w_{1}}\left(\frac{\int_{0}^{f_{t}} c(f) d f}{c_{t}^{0}}\right)^{w_{2}}=\left[1-\left(f_{t}+\Delta f\right)\right]^{w_{1}}\left(\frac{\int_{0}^{f_{t}+\Delta f} c(f) d f}{c_{t}^{0}}\right)^{w_{2}}$

Therefore:

$$
c(f)=\frac{\lambda}{(1-f)^{\frac{1}{w_{2}}}}=\frac{\lambda}{(1-f)^{\frac{1}{1-w_{1}}}}
$$

...where $\lambda$ is a constant.

The trend of $c(f)$ is shown in Fig. 1.

From Fig. 1, the marginal unit compensation price that users are satisfied with increases as the proportion of the load interrupted by LA to the maximum interruptible load of a user increases. And the larger $w_{2}$ is, the slower the marginal unit compensation price increases, indicating that when the user is sensitive to the compensation amount, a little price increase can satisfy the user.

Because $w_{2}$ of each user is different, LA needs to find a value of $w_{2}$ and compensate users with $c(f)$ of the value of $w_{2}$. Users whose $w_{2}$ are above the value are willing to participate in it, and users whose $w_{2}$ are below the value are not willing to participate in it.

The amount of compensation of LA for the interruptible load of all users for one day is:

$$
\begin{aligned}
B_{1} & =\sum_{t=1}^{T} \sum_{i=1}^{N_{1}} b_{1, i, t} \\
& =\sum_{t=1}^{T} \sum_{i=1}^{N_{1}} \int_{0}^{f_{t, i}} \frac{\lambda}{(1-f)^{\frac{1}{w_{2}}}} p_{t, i}^{0} d f \\
& =\sum_{t=1}^{T} \sum_{i=1}^{N_{1}} \lambda p_{t, i}^{0} \frac{w_{2}}{w_{1}}\left[\left(1-f_{t, i}\right)^{-\frac{w_{1}}{w_{2}}}-1\right]
\end{aligned}
$$

...where $p_{t, i}^{0}$ is the maximum load that the user can interrupt at time $t, f_{t, i}$ is the proportion of interrupted load to the maximum interruptible load of the $i$ th user, $b_{1 t, i}$ is the compensation amount of the interruptable load of the user at time $t, \mathrm{~T}$ is the number of periods divided by one day, and $N_{1}$ is the number of users participating in it.

The compensation of the grid company to LA should be higher than compensation of LA to users to encourage LA to participate in it:

$$
c_{1}(f)=\alpha c(f)=\alpha \frac{\lambda}{(1-f)^{\frac{1}{w_{2}}}} \quad(\alpha>1)
$$

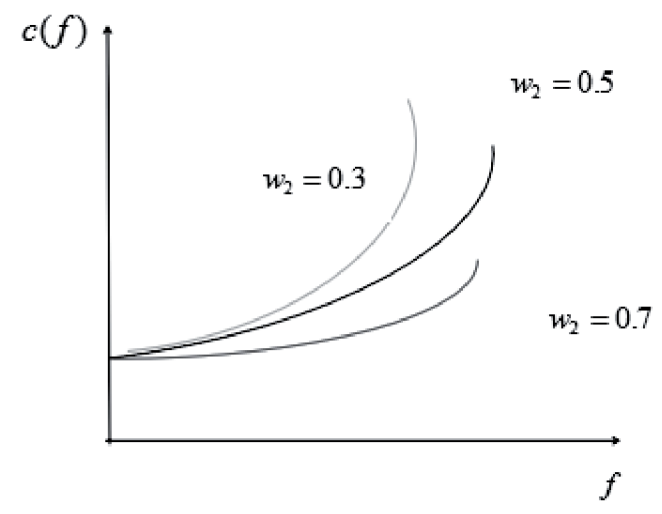

Fig. 1. Trend of $c(f)$ under different $w_{2}$.

...where $\alpha$ is the excitation coefficient and $c_{1}(f)$ is the marginal unit compensation price of the grid company to LA.

Suppose that the grid company has a maximum compensation amount $M_{t}$ at different time:

$$
c_{1, t}(f)=\left\{\begin{array}{cc}
\alpha \frac{\lambda}{(1-f)^{\frac{1}{w_{2}}}}, & f<1-\left(\frac{\alpha \lambda}{M_{t}}\right)^{w_{2}} \\
M_{t}, & 1-\left(\frac{\alpha \lambda}{M_{t}}\right)^{w_{2}} \leq f \leq 1
\end{array}\right.
$$

...where $c_{1, t}(f)$ is the marginal unit compensation price of the grid company to LA at time $t$. The relationship between $c_{1, t}(f)$ and $c(f)$ is shown in Fig. 2 .

From Fig. 2, when $f$ exceeds the critical point $E$, LA is still willing to increase the interruptible load until $c_{1, t}(f)$ intersects $c_{1}(f)$. The shaded part is the profit obtained by LA. The maximum proportion of interruptible load that LA is willing to interrupt can be solved:

$$
f_{t}^{\max }=1-\left(\frac{\lambda}{M_{t}}\right)^{w_{2}}
$$

According to (14), we have:

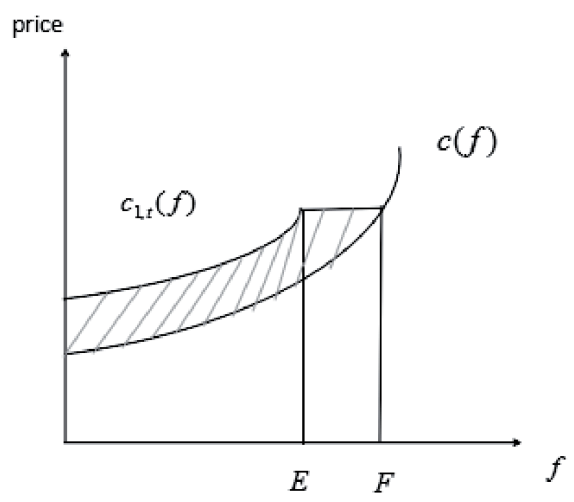

Fig. 2. Relationship between $c_{1, t}(f)$ and $c(f)$. 


$$
M_{t}=\frac{\lambda}{\left(1-f_{t}^{\max }\right)^{\frac{1}{w_{2}}}}
$$

The grid company needs to predict $f_{t}^{\max }$ during peak hours in advance, and then obtain $M_{t}$ and pass this information to LA.

Therefore, the compensation amount of the grid company to LA is:

$$
\begin{gathered}
B_{2}=\sum_{t=1}^{T} \int_{0}^{f_{t}^{\max }} \mathrm{c}_{1, \mathrm{t}}(f) \sum_{i=1}^{N_{1}} p_{t, i}^{0} \\
\text { Compensation Mechanism } \\
\text { of Transferable Load }
\end{gathered}
$$

Different from the interruptible load, the satisfaction degree of users does not decrease with the increase of the transferable load. Namely, the indicator of electricity consumption of users does not decrease with the increase of the transferable load. Therefore:

$$
\begin{gathered}
h=a \\
g=\frac{\int_{0}^{j_{0}} c(j) d j}{c_{t}^{0}} \\
w\left(j_{0}\right)=h^{w_{3}} g^{w_{4}} \\
j_{0}=\frac{p^{\prime}}{p^{0}}
\end{gathered}
$$

...where $h$ is indicator of electricity consumption of users, $a$ is a constant, $g$ is the indicator of compensation amount of users, $w_{3}$ is sensitivity of users to electricity consumption, $w_{4}$ is the sensitivity of users to the compensation amount, $p^{\prime}$ is the load that transferred by LA, $p^{0}$ is the maximum amount of transferable load, $j_{0}$ is the proportion of the load that transferred by LA to the maximum transferable load, and $w\left(j_{0}\right)$ is the satisfaction degree of users when the proportion of the load that transferred by LA to the maximum transferable load is $j_{0}$

To get the minimum marginal unit compensation price, we have:

$$
w\left(j_{0}\right)=w_{t}\left(j_{0}+\Delta j\right)
$$

... and:

$$
c(j)=0
$$

This means that the compensation that users expect is not related to the amount of transferable load, but is related to whether or not to participate in it. Therefore,
LA can aggregate the maximum transferable load capacity of users, and the amount of compensation for the transferable load of users is a fixed value.

In order to involve users with large charge levels in the project. LA can adopt a step compensation mechanism:

$$
b_{2}=\left\{\begin{array}{cc}
k_{1}, & 0<p^{0} \leq a_{1} \\
k_{2}, & a_{1}<p^{0} \leq a_{2} \\
k_{3}, & p^{0}>a_{2}
\end{array}\right.
$$

...where $a_{1}, a_{2}, k_{1}, k_{2}, k_{3}$ are all constants. Therefore:

$$
B_{3}=\sum_{i=1}^{N_{2}} b_{2, i}
$$

...where $B_{3}$ is the amount of compensation for all participating users for one day, $N_{2}$ is the number of users participating in it, and $b_{2, i}$ is the compensation amount of the transferable load for the $t$ th user.

The transferable load achieves the purpose of peak clipping and valley filling. Therefore, compensation of the grid company to LA should include the compensation for peak clipping and valley filling:

$$
\mathrm{B}_{4,1}=v \sum_{i=1}^{N_{2}} p_{i}^{0}
$$

...where $\mathrm{B}_{4,1}$ is compensation for peak clipping, $v$ is the unit price of the compensation for peak clipping, and $p_{i}^{0}$ is the amount of the transferable load of the $i$ th user.

If LA transfers all the transferable load to the same time, then a secondary peak will be formed and it is difficult for the generator set to reach the load requirement in a short time, which will affect the safe operation of the power grid. Therefore, the goal of the grid company should be translated into economic incentives for LA. The goal of the grid company is to achieve minimum grid load fluctuations [10]:

$$
\min \left[\frac{\sum_{t \in T_{3}}\left(P_{t}+D_{t}\right)^{2}}{T_{3}^{\prime}}-\left(\frac{\sum_{t \in T_{3}}\left(P_{t}+D_{t}\right)}{T_{3}^{\prime}}\right)^{2}\right]
$$

...where: $T_{3}$ is the set $\left\{1,2, \ldots, T_{3}^{\prime}\right\}, P_{t}$ is the load transferred to time $t$, and $D_{t}$ is non-deferrable load a at time t.

Since the total transferable load and $T_{3}^{\prime}$ are fixed, (26) can be simplified as:

$$
\min \left[\sum_{t \in T_{3}}\left(P_{t}+D_{t}\right)^{2}\right]
$$

Make Eq. (27) dimensionless, we have: 


$$
\begin{aligned}
\eta & =\frac{\sum_{t \in T_{3}}\left(P_{t}+D_{t}\right)^{2}}{T_{3}^{\prime}\left(\frac{\sum_{t \in T_{3}}\left(P_{t}+D_{t}\right)}{T_{3}^{\prime}}\right)^{2}} \\
& =\frac{T_{3}^{\prime} \sum_{t \in T_{3}}\left(P_{t}+D_{t}\right)^{2}}{\left(\sum_{t \in T_{3}}\left(P_{t}+D_{t}\right)\right)^{2}}
\end{aligned}
$$

The grid company can convert Eq. (28) into compensation for valley filling:

$$
\sum_{i=1}^{N_{2}} p_{i}^{0}\left(\eta_{0}-\eta\right)
$$

...where $\gamma$ is coefficient compensation for valley filling, and $\eta_{0}$ is the threshold of the load fluctuation. If $\eta \leq \eta_{0}$, then LA will get an economic reward. If $\eta>\eta_{0}$, LA will get economic punishment.

Therefore, the compensation amount of the grid company to LA is:

$$
\begin{gathered}
B_{4}=\mathrm{B}_{4,1}+\mathrm{B}_{4,2} \\
=v \sum_{i=1}^{N_{2}} p_{i}^{0}+\gamma \sum_{i=1}^{N_{2}} p_{i}^{0}\left(\eta_{0}-\eta\right)
\end{gathered}
$$

\section{Costs and Benefits}

The costs of users include the costs of purchase and installation of the equipment shared by users and maintenance of the equipment:

$$
\mathrm{C}_{u}=N_{3}\left(\varepsilon_{1} C_{s}+q C_{w}\right)
$$

...where $\mathrm{C}_{u}$ is the costs of all users, $N_{3}$ is the number of users, $\varepsilon_{1}$ is the proportion of costs of the equipment shared by users, $C_{w}$ is the annual maintenance costs of the equipment, and $q$ is the number of years of the project.

The benefits of users include the compensation of LA to users:

$$
\mathrm{R}_{u}=\sum_{i=1}^{q}\left(B_{1, i}^{\prime}+B_{3, i}^{\prime}\right)
$$

...where $B_{1, i}^{\prime}$ is the compensation of the interruptable load of LA to users in the ith year, and $B_{3, i}^{\prime}$ is the compensation of the transferable load of LA to users in the $i$ th year.

According to (31) and (32), we have:

$$
\begin{gathered}
\pi_{u}=\mathrm{R}_{u}-\mathrm{C}_{u} \\
=\sum_{i=1}^{q}\left[B_{1, i}^{\prime}+B_{3, i}^{\prime}+c_{g} \mathrm{p}_{x, i}+\left(c_{g}-c_{d}\right) \mathrm{p}_{z, i}\right]- \\
-N_{3}\left(\varepsilon_{1} C_{s}+q C_{w}\right)
\end{gathered}
$$

The costs of LA include purchase and installation of the equipment shared by LA, the compensation of LA to users and annual management costs [11]:

$$
C_{a}=\varepsilon_{2} N_{3} C_{s}+\sum_{i=1}^{q}\left(B_{1, i}^{\prime}+B_{3, i}^{\prime}+C_{y a}\right)
$$

...where $\varepsilon_{2}$ is the proportion of cost of the equipment shared by LA, and $C_{y a}$ is annual management cost of LA.

The benefits of LA include the compensation of the grid company to LA:

$$
\mathrm{R}_{a}=\sum_{i=1}^{q}\left(B_{2, i}^{\prime}+B_{4, i}^{\prime}\right)
$$

...where $B_{2, i}^{\prime}$ is the compensation of the interruptable load of the grid company to LA in the $i$ th year, and $B_{4, i}^{\prime}$ is the compensation of the transferable load of the grid company to LA in the $i$ th year.

According to (34) and (35), we have:

$$
\begin{gathered}
\pi_{a}=\mathrm{R}_{a}-\mathrm{C}_{a} \\
=\sum_{i=1}^{q}\left(B_{2, i}^{\prime}+B_{4, i}^{\prime}-B_{1, i}^{\prime}-B_{3, i}^{\prime}-C_{y a}\right)-\varepsilon_{2} N_{3} C_{s}
\end{gathered}
$$

...where $\pi_{a}$ is the profits of LA.

The costs of the grid company include purchase and installation of the equipment shared by the grid company, the compensation of the grid company to LA and annual management costs:

$$
C_{p}=\varepsilon_{3} N_{3} C_{s}+\sum_{i=1}^{q}\left(B_{2, i}^{\prime}+B_{4, i}^{\prime}\right)
$$

...where $\varepsilon_{3}$ is the proportion of costs of the equipment shared by the grid company, and $C_{y p}$ is annual management costs of the grid company.

The benefits of LA include the costs of the reduced capacity and reduced electricity at peak times:

$$
\mathrm{R}_{p}=\sum_{i=1}^{q}\left[\mathrm{c}_{n} \mathrm{~V}_{i}+\mathrm{p}_{x, i}\left(\mathrm{c}_{f}+c_{q}\right)\right]
$$

...where $c_{n}$ is the average unit cost of substation and transmission line, $c_{f}$ is the average unit cost of power purchase of the grid company, $\mathrm{V}_{i}$ is the capacity reduced in the $i$ th year, $\mathrm{p}_{x, i}$ is the load interrupted by LA in the $i$ th year, and $c_{q}$ is the unit costs of network loss and transportation.

According to (35) and (36), we have:

...where $\pi_{u}$ is the profits of users. 


$$
\begin{gathered}
\pi_{p}=\mathrm{R}_{p}-C_{p} \\
=\sum_{i=1}^{q}\left[\mathrm{c}_{n} \mathrm{~V}_{i}-B_{2, i}^{\prime}-B_{4, i}^{\prime}-C_{y p}+\mathrm{p}_{x, i}\left(\mathrm{c}_{f}+c_{q}\right)\right]- \\
-\varepsilon_{3} N_{3} C_{s}
\end{gathered}
$$

...where $\pi_{a}$ is the profits of the grid company.

\section{Results and Discussion}

The Optimal Value of $w_{2}$

When $w_{2}$ of each user obeys truncated normal distribution at $0-1$, we have:

$$
f\left(w_{2}, \mu, \delta, 0,1\right)=\frac{\frac{1}{\delta} \phi\left(\frac{w_{2}-\mu}{\delta}\right)}{\Phi\left(\frac{1-\mu}{\delta}\right)-\Phi\left(\frac{0-\mu}{\delta}\right)}
$$

If the grid company wants to reduce the load of the maximum interruptible load of all users by $25 \%$ at the peak, the number of users is $n$, the maximum load that each user can interrupt at the peak time is the same, $f_{\mathrm{t}}$ of all users are the same, and the participation rate of users is $\theta$, we have:

$$
\mathrm{B}_{1}=\lambda n \theta p_{t}^{0} \frac{w_{2}}{w_{1}}\left[\left(1-\frac{0.25}{\theta}\right)^{-\frac{w_{1}}{w_{2}}}-1\right]
$$

When $\mu=0.5, \delta=0.2, \mathrm{n}=1000, \lambda=0.4, p_{t}^{0}=1 \mathrm{kwh}$, we have Table 1.

From Table 1, the participation rate of users decreases with the increase of $w_{2}$, and the compensation first decreases and then increases with the increase of $w_{2}$. When $w_{2}=0.38, \mathrm{~B}_{1}$ reaches the minimum and the participation rate of users is $72.78 \%$.

\section{Compensation of One Day}

Suppose that the maximum interruptible load accounts for $30 \%$ of the total load at peak time. The peak time is from 18:00 to 22:00 and LA reduces the maximum interruptible load of all users by $25 \%$ at the peak. This paper selects electric vehicles as the transferable load. Suppose that the penetration rate of electric vehicles is $30 \%$ and electric vehicles of all users are the same. The charging power of the electric vehicles is $9.6 \mathrm{KW}$, and the power consumption is $19.5 \mathrm{kwh} / 100 \mathrm{~km}$. Daily travel distance of users obeys a normal distribution (19.68, 1.142) and the time that users start charging obeys a normal

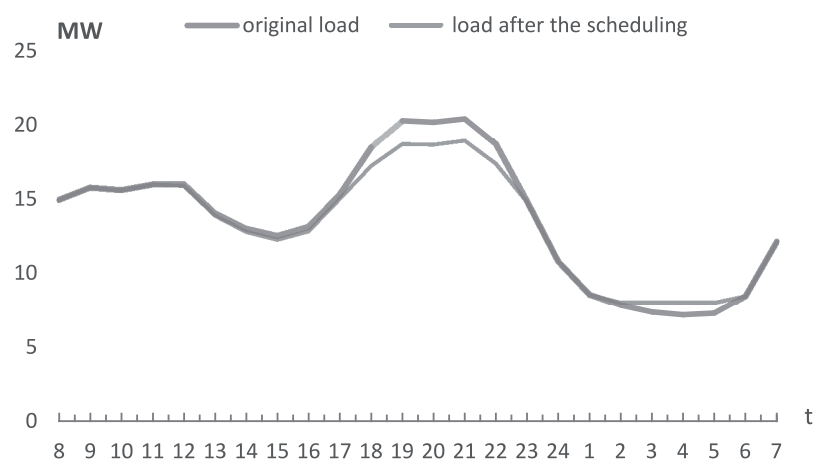

Fig. 3. Original load and the load after scheduling.

distribution $\left(17.47,13.41^{2}\right)$ [25]. Other data are as follows: $v=0,2 \gamma=0.05, \eta_{0}=1.2, \alpha=1.8$.

$$
b_{2}=\left\{\begin{array}{lc}
1 \text { yuan }, & 0<p^{0} \leq 6 k w h \\
2 \text { yuan }, & 6 k w h<p^{0} \leq 14 k w h \\
3 \text { yuan, } & p^{0}>14 k w h
\end{array}\right.
$$

The original load and the load after the scheduling are shown in Fig. 3:

From Fig. 3, after the scheduling, the load during the peak is significantly reduced, and the part of the load at the peak is transferred to the valley. The peak load before scheduling is $20.41 \mathrm{MW}$ and the peak and valley difference is $64.54 \%$. The peak load after scheduling is $18.94 \mathrm{MW}$ and the peak and valley difference is $54.08 \%$. If the increased electricity in the valley belongs to wind power, the amount of abandoned wind power is reduced by $2.09 \mathrm{MWh}$ and thermal power generation is reduced by $8.56 \mathrm{MWh}$, which is equivalent to reducing emissions of $8.22 \mathrm{t}$ carbon dioxide. The compensation is shown in Table 2.

\section{Long-Term Profit of Each Participant}

The relevant data is as follows. The costs of purchase and installation of the equipment is 6,000 yuan per user, which is divided equally by the three participants.

Table 2. Compensation of LA to users and the grid company to LA.

\begin{tabular}{|c|c|c|c|c|}
\hline & $B_{1}$ & $B_{2}$ & $B_{3}$ & $B_{4}$ \\
\hline Total amount/yuan & 3387 & 5781 & 344 & 543 \\
\hline Average/ (yuan/KWh) & 0.5312 & 0.901 & 0.164 & 0.2600 \\
\hline
\end{tabular}

Table 1. Participation rate of users and the compensation at the peak under different.

\begin{tabular}{|c|c|c|c|c|c|c|c|c|}
\hline$w_{2}$ & 0.2 & 0.3 & 0.37 & 0.38 & 0.39 & 0.4 & 0.41 & 0.5 \\
\hline$\theta / \%$ & 93.83 & 84.56 & 74.58 & 72.78 & 71.15 & 69.39 & 67.58 & 50 \\
\hline $\mathrm{B}_{1} /$ yuan & 230.20 & 183.44 & 176.04 & 175.96 & 176.16 & 176.60 & 177.32 & 200.00 \\
\hline
\end{tabular}




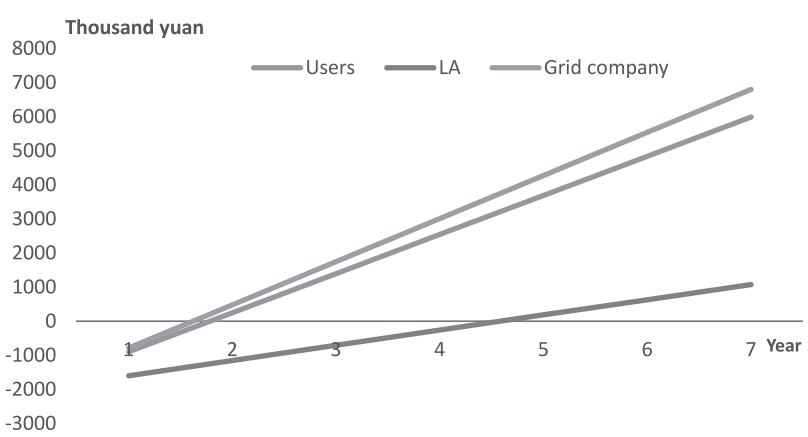

Fig. 4. Long-term profits of each participant.

Table 3. Time required to achieve profitability under different proportions of equipment costs of each participant.

\begin{tabular}{|c|c|c|c|c|c|}
\hline \multicolumn{2}{|c|}{$\begin{array}{c}\text { Proportion of each } \\
\text { participant }\end{array}$} & \multicolumn{3}{|c|}{$\begin{array}{c}\text { Time required to achieve } \\
\text { profitability/year }\end{array}$} \\
\hline$\varepsilon_{1}$ & $\varepsilon_{1}$ & $\varepsilon_{1}$ & Users & LA & Grid company \\
\hline 0.3 & 0.3 & 0.4 & 1.60 & 4.13 & 1.94 \\
\hline 0.2 & 0.2 & 0.6 & 1.07 & 2.75 & 2.91 \\
\hline 0.2 & 0.1 & 0.7 & 1.07 & 1.38 & 3.40 \\
\hline 0.15 & 0.15 & 0.7 & 0.80 & 2.06 & 3.40 \\
\hline
\end{tabular}

The maintenance per user is 100 yuan/year. The annual management cost of LA is 400,000 yuan/year and the annual management cost of the grid company is 200,000 yuan/year. The costs of grid transmission and loss are 0.186 yuan $/ \mathrm{kWh}$ and the average unit cost of power purchase is 0.414 yuan/kWh. The average unit cost of substation and transmission line is 1610 yuan/kW. The long-term profits of each participant are shown in Fig. 4.

From Fig. 4, each participant can make profits under this compensation mechanism. The grid company has the fastest profit growth. It takes 1.62 years for the grid company to achieve profitability, 4.58 years for LA to achieve profitability, and 1.78 years for users to achieve profitability. In order to motivate users and LA to participate in the project, it is necessary to properly allocate the costs of the equipment [11].

From Table 3, when the proportion of costs of the equipment are shared by users, LA and the grid company is $0.2,0.1$ and 0.7 respectively, and the time required to achieve profitability of users, LA and the grid company is 1.07, 1.38 and 3.40 years. Under the proportion of each participant, users and LA are more willing to participate in this project.

\section{Conclusions}

This paper studies the marginal unit compensation price of interruptible load and the transferable load on the basis of the satisfaction degree of users. The marginal unit compensation price of interruptible load increases with the increase of the proportion of the load interrupted by LA to the maximum interruptible load of users. Therefore, the load interrupted by LA should be proper. The compensation that users expect is not related to the amount of transferable load, Therefore, LA can aggregate the maximum transferable load capacity of users and should make full use of transferable load resources of users to get more profits.

From the case study, the load during the peak and carbon dioxide emissions can be reduced through load aggregation. Each participant can make profits under this compensation mechanism. To attract users and LA to participate in this project, the grid company should bear more expenses of the equipment, so that users and LA can make profits in a short period of time.

\section{Acknowledgements}

This work was supported by the Fundamental Research Funds for the Central Universities (No. 2016MS126).

\section{Conflict of Interest}

The authors declare no conflict of interest.

\section{References}

1. Jiangsu electric power company 2017 corporate information disclosure annual report, Http://www.js.sgcc. com.cn/html/main/col2747/201804/27/20180427165614237 565943_1.html, (accessed on 10, 10, 2018).

2. WANG B.B, ZHU F, JI W.L, CAO Y. Load cutting potential modeling of central air-conditioning and analysis on influencing factors. automation of electric power systems, 40 (19), 44, 2016.

3. FERA M., MACCHIAROLI R., IANNONE R., MIRANDA S., RIEMMA S. Economic evaluation model for the energy Demand Response. Energy, 112, 457, 2016.

4. GAO C.W., LI Q.Y., LI H.X., ZHAI H.B., ZHANG L. Methodology and Operation Mechanism of Demand Response Resources Integration Based on Load Aggregator. Automation of Electric Power Systems, 37 (17), 78, 2013.

5. YAO S.C., LIU H.M., DAN L., YUAN X.L. Time-space characteristic of interruptible load on dispatch solution. IFAC PapersOnLine, 48 (28), 2015.

6. LIU W.X., LI X.Y., LIU Z.M., WANG A., WANG J.W. Energy operator operating mode and energy management based on stackelberg game. Modern Electric Power, 35 (2), $8,2018$.

7. LIU X.F., GAO B.T., LUO J., TANG W. Non-cooperative Game Based Hierarchical Dispatch Model of Residential Loads, Modern Electric Power, 41 (14), 54, 2017.

8. SUN Y., ZHAO J., LI B., XU P., LI X.1. Assessment method for demand side user response potential considering information value. Journal of Electric Power Science and Technology, 32 (1), 3, 2017. 
9. LI C., WANG D., ZHANG P., XIE K.G. Double layer real-time scheduling model of independent microgrid considering scheduling priority of load aggregators. Automation of Electric Power System, 41 (6), 37, 2017.

10. HU Z.C., ZHAN K.Q., ZHANG H.C., SONG Y.H. Pricing mechanisms design for guiding electric vehicle charging to fill load valley. Applied Energy, 178, 155, 2016.

11. ZHANG J.Y, WANG L., LIU S.G. Cost-benefit analysis of load aggregator participating in interruptible load program. Southern Power System Technology, 10 (8), 74, 2016.

12. BEHRANGRAD M., SUGIHARA H., FUNAKI T. Integrating the cold load pickup effect of reserve supplying demand response resource in social cost minimization based system scheduling. Energy, 45 (1), 1034, 2012.

13. MUKHERJEE J.C., SHUKLA S., GUPTA A. Mobility aware scheduling for imbalance reduction through charging coordination of electric vehicles in smart grid. Pervasive and Mobile Computing, 21, 104, 2015.

14. JIANG D.R., XIANG H.W., WANG Y.W. Load aggregator incentive pricing scheme based stackelberg game and flexible loads dispatching research. Journal of Chongqing University of Technology (Natural Science), 5, 169, 2018.

15. MAZIDI M., MONSEF H., SIANO P. Design of a riskaverse decision making tool for smart distribution network operators under severe uncertainties: An IGDT-inspired augment $\varepsilon$-constraint based multi-objective approach. Energy, 116, 214, 2016.

16. NAZARI M., FOROUD A.A . Optimal strategy planning for a retailer considering medium and short-term decisions. International Journal of Electrical Power and Energy Systems, 45 (1), 107, 2013.

17. AHMADI A., CHARWAND M., SIANO P.,ALI ESMAEEL, NEZHAD D.S., GITIZADEH M., RAEISI
F. A novel two-stage stochastic programming model for uncertainty characterization in short-term optimal strategy for a distribution company. Energy, 117, 1, 2016.

18. RUIZ N., CLAESSENS B., JIMENO J., LÓPEZ J. A., SIX D. Residential load forecasting under a demand response program based on economic incentives. European transactions on electrical power, 25 (8), 1436, 2015.

19. SUSANNA M., NICOLA N., FABRIZIO P., SIMON R.,. Demand side integration in LV smart grids with multiagent control system. Electric Power Systems Research, 125, 23, 2015.

20. LAKSHMANAN V., MARINELLI M., M. KOSEK A., NORGÅRD P., W. BINDNER H. Impact of thermostatically controlled load demand response activation on aggregated power: A field experiment. Energy, 94, 705, 2016.

21. ŠKUGOR B., DEUR J. Dynamic programming-based optimization of charging an electric vehicle fleet system represented by an aggregate battery model. Energy, 92, 456, 2015.

22. CORTÉS A., MARTÍNEZ S. A hierarchical algorithm for optimal plug-in electric vehicle charging with usage constraints. Automatica, 68, 119, 2016.

23. FERA M., MACCHIAROLI R., IANNONE R., MIRANDA S., RIEMMA S. Economic evaluation model for the energy Demand Response. Energy, 112, 457, 2016.

24. BEHRANGRAD M., SUGIHARA H., FUNAKI T. Integrating the cold load pickup effect of reserve supplying demand response resource in social cost minimization based system scheduling. Energy, 45 (1), 1034, 2012.

25. RAVIKIRAN V., KUMAR K.R. Review on Contactless Power Transfer for Electric Vehicle Charging. Energies, 10 (5), 636, 2017. 